\title{
FONTES DE FÓSFORO NO CRESCIMENTO DE PORTA-ENXERTO DE SERINGUEIRA SOB CONDIÇÕES DE VIVEIRO
}

\author{
Elaine Cristine Piffer Gonçalves ${ }^{1}$, Renato de Mello Prado $^{2}$, Marcus André Ribeiro Correia ${ }^{3}$ \\ ${ }^{1}$ Eng ${ }^{\mathrm{a}}$ Agrônoma, Dr ${ }^{\mathrm{a}}$, Pólo Regional de Desenvolvimento Tecnológico dos Agronegócios da Alta Mogiana, Colina, SP, Brasil - \\ elainegoncalves@apta.sp.gov.br \\ ${ }^{2}$ Eng. Agrônomo, Dr., Depto. de Solos e Adubos, FCAV/UNESP, Jaboticabal, SP, Brasil - rmprado@ @ fcav.unesp.br \\ ${ }^{3}$ Eng. Agrônomo, Doutorando em Produção Vegetal, FCAV/UNESP, Jaboticabal, SP, Brasil - marcus.agro@ hotmail.com
}

Recebido para publicação: 04/08/2009 - Aceito para publicação: 17/03/2010

\begin{abstract}
Resumo
O uso de fontes e doses de fósforo podem influenciar o crescimento do porta-enxerto de seringueira. Objetivou-se avaliar os efeitos da aplicação de diferentes fontes de fósforo no crescimento de portaenxertos de seringueira sob condições de viveiro. Para isso, realizou-se experimento em viveiro telado, em Colina/SP. O delineamento experimental foi em blocos ao acaso, com cinco tratamentos e quatro repetições. Os tratamentos foram constituídos de: 1-testemunha (sem aplicação de P); $2-2,5 \mathrm{~kg}$ de superfosfato simples e $186 \mathrm{~g}$ de óxido silicatado por $\mathrm{m}^{3}$ de terra; 3- 5,0 $\mathrm{kg}$ de superfosfato simples e $372 \mathrm{~g}$ de óxido silicatado por $\mathrm{m}^{3}$ de terra; 4 - $3,1 \mathrm{~kg}$ de termofosfato magnesiano por $\mathrm{m}^{3}$ de terra; 5$6,2 \mathrm{~kg}$ de termofosfato magnesiano por $\mathrm{m}^{3}$ de terra. A parcela foi constituída por cinco sacolas plásticas de dimensões de $20 \times 35 \mathrm{~cm}$, contendo uma muda de seringueira (clone Tjair). Ao longo do cultivo do porta-enxerto da seringueira, realizou avaliações do crescimento, a partir do diâmetro do caule a $5 \mathrm{~cm}$ do solo e a altura das plantas, durante seis épocas (junho/2008, agosto/2008, outubro/2008, janeiro/2009, março/2009 e maio/2009) de cultivo. A aplicação do fósforo incrementou o crescimento das plantas, durante todo o ciclo de crescimento das mudas de seringueira. Para produção de mudas de seringueira indica-se aplicação do fósforo, seja na forma de termofosfato na dose de $3,1 \mathrm{~kg}$ por $\mathrm{m}^{3}$ de terra ou na forma do superfosfato simples na dose de $2,5 \mathrm{~kg}$ por $\mathrm{m}^{3}$ de terra. Palavras-chave: Hevea brasiliensis; produção de mudas; desenvolvimento; adubação fosfatada.
\end{abstract}

\begin{abstract}
Sources of phosphorus on rootstock growth of nursery cultured seringueira. The use of phosphorous sources and s levels can influence the growth of rubber tree rootstockr. This research aimed to evaluate the effects of application of different phosphorus sources on growth of rubber tree rootstock under nursery conditions, int an experiment carried out in a greenhouse located in Colina County, São Paulo State, Brazil. The experimental design was randomized blocks with five treatments and four replications. The treatments consisted of: 1 -control (no $\mathrm{P}$ application), $2-2.5 \mathrm{~kg}$ superphosphate and $186 \mathrm{~g}$ of silicate oxide per $\mathrm{m}^{3}$ of earth, $3-5.0 \mathrm{~kg}$ of superphosphate and $372 \mathrm{~g}$ oxide silicate per $\mathrm{m}^{3}$ of earth, $4-3.1 \mathrm{~kg}$ of thermophosphate per $\mathrm{m}^{3}$ of earth, from 5 to $6.2 \mathrm{~kg}$ of thermophosphate per $\mathrm{m}^{3}$ of earth. The plot consisted of five plastic bags of $20 \times 35 \mathrm{~cm}$, containing a rubber trees seedling (clone Tjair). Evaluations of stem diameter and seedling height growths were carried out during six sesaons (June/2008 to May/2009). Phosphorus application increased the plants growth throughout the seasons. Application of phosphorous is indicated to the rubber tree seedling production, either in the form of thermophosphate $\left(3.1 \mathrm{~kg}\right.$ per $\mathrm{m}^{3}$ of soil) or in the form of single superphosphate $(2.5 \mathrm{~kg}$ per $\mathrm{m}^{3}$ of soil).

Keywords: Hevea brasiliensis; seedlings; development; phosphate fertilization and thermophosphate.
\end{abstract}

\section{INTRODUÇÃO}

Embora mais de 2000 espécies de plantas superiores produzam látex com poli-isoprenos (borracha natural), apenas a seringueira (Hevea brasiliensis Muell. Arg.) estabeleceu-se como espécie-chave na produção comercial de borracha, em função da excelente qualidade da borracha e de seus subprodutos (ASAWATRERATANAKUL et al., 2003). Com propriedades únicas entre os produtos naturais poliméricos, a 
borracha natural combina elasticidade, plasticidade, resistência ao desgaste (fricção), propriedades de isolamento elétrico e impermeabilidade a líquidos e gases (GONÇALVES et al., 1990).

A heveicultura é um investimento a longo prazo, portanto a estratégia de implantação do seringal deve ser bem planejada. O sucesso da implantação depende, basicamente, do desempenho em termos de produção do material selecionado e das técnicas utilizadas.

O aumento da produtividade da borracha natural é extremamente importante para o Brasil, visto que sua atual produção não atende plenamente a demanda interna. A despeito de todo o avanço conseguido com pesquisas nacionais, o Brasil ainda não consegue suprir o mercado interno de látex, necessitando ainda importar em torno de $65 \%$ do que consome e contribuindo com apenas cerca de $1 \%$ da produção mundial.

Em São Paulo, a heveicultura tornou-se uma das poucas opções de cultivo permanente para sustentação do desenvolvimento de várias regiões e é crescente e notória sua expansão para novas áreas. Com essa expansão, a cultura está ocupando solos marginais, de baixa fertilidade, ácricos e álicos, sendo que as práticas agrícolas adequadas, como correção da acidez e manejo da adubação, além do uso de clones indicados ao ambiente de produção, devem ser consideradas e constantemente reavaliadas, a fim de proporcionar a sustentabilidade da atividade agrícola. Assim, um dos nutrientes mais limitante em solos tropicais é o fósforo, e, segundo Shorrocks (1974), a deficiência desse nutriente em seringueira induz plantas pouco desenvolvidas, caules finos e pequeno número de folhas. Nas folhas deficientes apresentam um bronzeamento na parte inferior restrito em geral à metade distal da folha. Nesse sentido, existem algumas informações dos efeitos benéficos do fósforo na seringueira, especialmente após o terceiro ano (CARVALHO; BATISTA, 2004).

No Brasil existem diversas fontes de fósforo para uso na agricultura, como os fosfatos solúveis, termofosfatos, multifosfatos, fosfatos naturais e, ainda, os fertilizantes fosfatados parcialmente acidulados (LANA et al., 2004). Os termofosfatos são os fosfatos silicatados mais conhecidos no Brasil.

O termofosfato magnesiano é preparado por fusão de mistura de fosfato e serpentina, formando o silicato de magnésio. O material é resfriado e moído, até se transformar em um pó fino. O autor ressalta, ainda, que os termofosfatos são adubos eficientes em solos ácidos, sendo corretivos de acidez e fornecedores de magnésio, silício e cálcio, além de fósforo (RAIJ, 1991). Estudos apontam a viabilidade técnica de sua utilização, principalmente em solos que apresentam condições adversas ao emprego dos fertilizantes tradicionais (YASUDA, 1989; MORELLI et al., 1991). O uso do termofosfato tem ação fertilizante, fornecendo, além do fósforo, cálcio e magnésio e alguns micronutrientes, e o elemento benéfico silício e ainda tem efeito corretivo, podendo neutralizar a acidez do solo. Baldeón (1995), por sua vez, admite que o efeito favorável do termofosfato magnesiano sobre o aproveitamento de fósforo pela planta se deve mais à sua capacidade de elevação de $\mathrm{pH}$ do solo.

No Brasil existem indicações de que as fontes de fósforo termofosfatos e superfosfatos apresentam eficiência agronômica semelhante (GOEDERT; LOBATO, 1984; OLIVEIRA, 1984).

$\mathrm{O}$ uso do termofosfato como fonte de fósforo na produção de porta-enxertos de culturas perenes é promissor, pois poderia, com efeito residual, beneficiar inclusive o crescimento inicial da cultura no campo. Assim, existe indicação do efeito benéfico dessa fonte no crescimento de porta-enxerto de plantas perenes, como a nespeira (GONZAGA et al., 2008), e no crescimento inicial de plantas de café (MELO, 2005), entretanto não foram encontrados trabalhos em porta-enxertos com a cultura da seringueira.

Nesse contexto, objetivou-se avaliar os efeitos da aplicação de diferentes fontes de fósforo no crescimento de porta-enxertos sob condições de viveiro.

\section{MATERIAL E MÉTODOS}

O experimento foi desenvolvido em viveiro telado, situado no Polo Regional de Desenvolvimento Tecnológico dos Agronegócios da Alta Mogiana, em Colina/SP.

O delineamento experimental foi em blocos ao acaso, com cinco tratamentos e quatro repetições. Tratamentos: 1 - testemunha (sem aplicação de P); 2 - 2,5 $\mathrm{kg}$ de superfosfato simples e $186 \mathrm{~g}$ de óxido silicatado por $\mathrm{m}^{3}$ de terra; $3-5,0 \mathrm{~kg}$ de superfosfato simples e $372 \mathrm{~g}$ de óxido silicatado por $\mathrm{m}^{3}$ de terra; $4-3,1 \mathrm{~kg}$ de termofosfato magnesiano por $\mathrm{m}^{3}$ de terra; $5-6,2 \mathrm{~kg}$ de termofosfato magnesiano por $\mathrm{m}^{3}$ de terra. $\mathrm{O}$ termofosfato magnesiano e o óxido silicatado utilizados foram o Yoorin Master 1® e FTE BR12®, respectivamente. 
Os fertilizantes foram homogeneizados em um Latossolo Vermelho distrófico, coletado da camada de 0-20 cm de profundidade. Em seguida foram preenchidas as sacolas plásticas de dimensões $20 \times 35 \mathrm{~cm}$. A parcela foi constituída por cinco sacolas plásticas de dimensões de $20 \times 35 \mathrm{~cm}$, contendo uma muda de seringueira (clone Tjair). Os tratamentos fitossanitários como pulverizações foram realizados conforme necessidade, durante o período de condução do experimento.

Realizou-se fertirrigação com a aplicação de nitrogênio e potássio, conforme indicação de Benesi (1999), para produção de mudas de seringueira, utilizando-se o sulfato de amônia associado com formulado 20-00-20, parcelados em quatro vezes (outubro/2008, novembro/2008, janeiro/2009 e fevereiro/2009).

Ao longo do cultivo do porta-enxerto da seringueira (18 meses), realizaram-se avaliações do crescimento, a partir do diâmetro do caule a $5 \mathrm{~cm}$ do solo, e da altura das plantas, durante seis épocas de cultivo (junho/2008, agosto/2008, outubro/2008, janeiro/2009, março/2009 e maio/2009).

\section{RESULTADOS E DISCUSSÃO}

Foi observado que a aplicação do fósforo na forma de termofosfato magnesiano na dose de $3,1 \mathrm{~kg} \cdot \mathrm{m}^{-3}$ de terra promoveu maior incremento do diâmetro do caule das mudas, entretanto não diferiu dos demais tratamentos com a aplicação desse macronutriente, com exceção da testemunha, que apresentou o menor valor para essa variável para todas as épocas avaliadas, exceto a época 3 , em que o tratamento com superfosfato simples na dose de $5 \mathrm{~kg} \cdot \mathrm{m}^{-3}$ de terra foi semelhante à testemunha (Tabela 1).

A aplicação do fósforo na forma de termofosfato na dose de 3,1 ou $6,2 \mathrm{~kg}$ por $\mathrm{m}^{3}$ de terra promoveu maior incremento da altura nas mudas, entretanto diferiu apenas da testemunha na época $1 \mathrm{e}$ da testemunha e da aplicação do superfosfato simples na dose de $5 \mathrm{~kg}$ na época 2.

$\mathrm{Na}$ época 3, a aplicação de fósforo, independentemente da fonte ou dose, foi semelhante no aumento da altura das mudas em relação à testemunha, enquanto na época 4 os tratamentos foram semelhantes, ou seja, não influenciaram no incremento em altura da planta. Na época 5, os tratamentos com uso do fósforo, independentemente da fonte, foram semelhantes na altura da muda, entretanto apenas a aplicação do P na forma de termofosfato na dose de $3,1 \mathrm{~kg}$ por $\mathrm{m}^{3}$ de terra promoveu maior altura na planta quando comparada à testemunha. Na última avaliação, todos os tratamentos com o $\mathrm{P}$ foram semelhantes no incremento da altura das mudas em relação à testemunha (Tabela 1). Observou-se, ainda, que a relação altura e diâmetro do caule diminuiu com o desenvolvimento do porta-enxerto, sendo de (em médias dos tratamentos) 13,6 e 9,3 na primeira e na última avaliação, respectivamente (Tabela 1). Isso indica que a planta de seringueira, ao longo do desenvolvimento, privilegia o acúmulo de biomassa do caule em detrimento da altura.

Nota-se que os efeitos do fósforo no incremento do diâmetro do caule e na altura de mudas de seringueira ocorreram devido ao fato de que esse nutriente desempenha uma função estrutural, fazendo parte de compostos orgânicos vitais para o crescimento das plantas, tendo destaque o ATP, portanto sendo agente importante na transferência de energia para todas as sínteses orgânicas das plantas (PRADO, 2008).

Portanto, observa-se que na maioria das épocas avaliadas houve semelhança entre as fontes de fósforo no crescimento das mudas de seringueira. Embora na cultura da seringueira não tenham sido encontrados trabalhos comparando as duas fontes de fósforo, em culturas anuais, em que se concentram a maioria dos trabalhos, existem indicações de que as fontes termofosfatos e superfosfatos apresentam eficiências agronômicas semelhantes (GOEDERT; LOBATO, 1984; OLIVEIRA, 1984). Em plantas perenes, como cafeeiro, Melo et al. (2005) também observaram efeitos semelhantes dessas fontes de fósforo no diâmetro do caule e na altura das plantas. Em plantas de melão cultivadas em vasos em dois Argissolos, houve semelhança na produção de matéria seca entre superfosfato e termofosfato, entretanto, em um Vertissolo, o superfosfato destacou-se em relação ao termofosfato (FARIA et al., 2006).

Os efeitos benéficos do uso do termofosfato no crescimento dos porta-enxertos de seringueira concordam com indicação geral de Yasuda (1989); Morelli et al. (1991) e Gonzaga et al. (2008), que relataram a viabilidade de uso dessa fonte de fósforo na agricultura.

De forma geral, os fertilizantes fosfatados, nas diferentes doses de fósforo, foram semelhantes no crescimento dos porta-enxertos, especialmente na última avaliação. Sendo assim, a indicação da menor dose do nutriente mostra-se a mais promissora, por apresentar o menor custo, e, portanto, espera-se a melhor relação custo/benefício da adubação fosfatada para produção dos porta-enxertos. 
Tabela 1. Efeito da aplicação de diferentes fontes de fósforo no diâmetro do caule (mm), na altura $(\mathrm{cm})$ e na relação altura e diâmetro do caule ao longo de seis épocas de cultivo do porta-enxerto de seringueira.

Table 1. Effect of two sources of phosphorus in the stem diameter and height over six seasons of cultivation of the rootstock of rubber (June 2008 to May 2009).

\begin{tabular}{|c|c|c|c|}
\hline Tratamentos & Diâmetro caule & Altura & $\begin{array}{c}\text { Relação altura e } \\
\text { diâmetro }\end{array}$ \\
\hline \multicolumn{4}{|c|}{ Época de avaliação 1 (junho/2008) } \\
\hline 1 (Testemunha, sem fósforo) & $1,91 \mathrm{~B}$ & $23,20 \mathrm{~B}$ & 12,2 \\
\hline $2\left(2,5 \mathrm{~kg}\right.$ superfosfato simples $+186 \mathrm{~g}$ óxido $\left./ \mathrm{m}^{3}\right)$ & $2,39 \mathrm{AB}$ & $32,15 \mathrm{AB}$ & 13,5 \\
\hline $3\left(5,0 \mathrm{~kg}\right.$ superfosfato simples $+372 \mathrm{~g}$ óxido $\left./ \mathrm{m}^{3}\right)$ & $2,20 \mathrm{AB}$ & $33,65 \mathrm{AB}$ & 15,3 \\
\hline $4\left(3,1 \mathrm{~kg}\right.$ de termofosfato $\left./ \mathrm{m}^{3}\right)$ & $3,01 \mathrm{~A}$ & $39,35 \mathrm{~A}$ & 13,1 \\
\hline $5\left(6,2 \mathrm{~kg}\right.$ de termofosfato $\left./ \mathrm{m}^{3}\right)$ & $2,75 \mathrm{AB}$ & $37,80 \mathrm{~A}$ & 13,7 \\
\hline $\mathrm{F}$ & $3,87^{*}$ & $4,06^{*}$ & \\
\hline $\mathrm{CV}(\%)$ & 18,0 & 18,9 & \\
\hline \multicolumn{4}{|c|}{ Época de avaliação 2 (agosto/2008) } \\
\hline 1 (Testemunha, sem fósforo) & $3,27 \mathrm{C}$ & $38,65 \mathrm{C}$ & 11,8 \\
\hline $2\left(2,5 \mathrm{~kg}\right.$ superfosfato simples $+186 \mathrm{~g}$ óxido $\left./ \mathrm{m}^{3}\right)$ & $3,90 \mathrm{ABC}$ & $46,05 \mathrm{ABC}$ & 11,9 \\
\hline $3\left(5,0 \mathrm{~kg}\right.$ superfosfato simples $+372 \mathrm{~g}$ óxido $\left./ \mathrm{m}^{3}\right)$ & $3,56 \mathrm{BC}$ & $42,62 \mathrm{BC}$ & 12,0 \\
\hline $4\left(3,1 \mathrm{~kg}\right.$ de termofosfato $\left./ \mathrm{m}^{3}\right)$ & $4,30 \mathrm{~A}$ & $51,92 \mathrm{~A}$ & 12,1 \\
\hline $5\left(6,2 \mathrm{~kg}\right.$ de termofosfato $\left./ \mathrm{m}^{3}\right)$ & $4,26 \mathrm{AB}$ & $47,90 \mathrm{AB}$ & 11,2 \\
\hline $\mathrm{F}$ & $7,86^{* *}$ & $6,39^{* *}$ & \\
\hline $\mathrm{CV}(\%)$ & 8,2 & 8,8 & \\
\hline \multicolumn{4}{|c|}{ Época de avaliação 3 (outubro/2008) } \\
\hline 1 (Testemunha, sem fósforo) & $3,36 \mathrm{~B}$ & $45,15 \mathrm{~B}$ & 13,4 \\
\hline $2(2,5 \mathrm{~kg}$ superfosfato simples $+186 \mathrm{~g}$ óxido/m³ $)$ & $5,30 \mathrm{~A}$ & $56,55 \mathrm{AB}$ & 10,7 \\
\hline $3(5,0 \mathrm{~kg}$ superfosfato simples $+372 \mathrm{~g}$ óxido/m³ $)$ & $5,18 \mathrm{~A}$ & $57,70 \mathrm{AB}$ & 11,1 \\
\hline $4\left(3,1 \mathrm{~kg}\right.$ de termofosfato $\left./ \mathrm{m}^{3}\right)$ & $5,55 \mathrm{~A}$ & $60,85 \mathrm{~A}$ & 11,0 \\
\hline $5\left(6,2 \mathrm{~kg}\right.$ de termofosfato $\left./ \mathrm{m}^{3}\right)$ & $5,34 \mathrm{~A}$ & $59,15 \mathrm{~A}$ & 11,1 \\
\hline $\mathrm{F}$ & $10,84^{* *}$ & $4,06^{*}$ & \\
\hline $\mathrm{CV}(\%)$ & 10,9 & 11,0 & \\
\hline \multicolumn{4}{|c|}{ Época de avaliação 4 (janeiro/2009) } \\
\hline 1 (Testemunha, sem fósforo) & $6,12 \mathrm{~B}$ & 70,60 & 11,6 \\
\hline $2\left(2,5 \mathrm{~kg}\right.$ superfosfato simples $+186 \mathrm{~g}$ óxido $\left./ \mathrm{m}^{3}\right)$ & $7,25 \mathrm{AB}$ & 75,65 & 10,4 \\
\hline $3\left(5,0 \mathrm{~kg}\right.$ superfosfato simples $+372 \mathrm{~g}$ óxido $\left./ \mathrm{m}^{3}\right)$ & $7,20 \mathrm{AB}$ & 74,65 & 10,4 \\
\hline $4\left(3,1 \mathrm{~kg}\right.$ de termofosfato/ $\left.\mathrm{m}^{3}\right)$ & $7,85 \mathrm{~A}$ & 78,50 & 10,0 \\
\hline $5\left(6,2 \mathrm{~kg}\right.$ de termofosfato $\left./ \mathrm{m}^{3}\right)$ & $7,50 \mathrm{~A}$ & 76,35 & 10,2 \\
\hline $\mathrm{F}$ & $4,80^{*}$ & $0,88^{\text {ns }}$ & \\
\hline $\mathrm{CV}(\%)$ & 8,2 & 8,2 & \\
\hline \multicolumn{4}{|c|}{ Época de avaliação 5 (março/2009) } \\
\hline 1 (Testemunha, sem fósforo) & $12,40 \mathrm{~B}$ & $112,55 \mathrm{~B}$ & 9,1 \\
\hline $2\left(2,5 \mathrm{~kg}\right.$ superfosfato simples $+186 \mathrm{~g}$ óxido $\left./ \mathrm{m}^{3}\right)$ & $15,20 \mathrm{AB}$ & $129,80 \mathrm{AB}$ & 8,5 \\
\hline $3\left(5,0 \mathrm{~kg}\right.$ superfosfato simples $+372 \mathrm{~g}$ óxido $\left./ \mathrm{m}^{3}\right)$ & $15,30 \mathrm{AB}$ & $132,15 \mathrm{AB}$ & 8,6 \\
\hline $4\left(3,1 \mathrm{~kg}\right.$ de termofosfato $\left./ \mathrm{m}^{3}\right)$ & $16,60 \mathrm{~A}$ & $138,50 \mathrm{AB}$ & 8,3 \\
\hline $5\left(6,2 \mathrm{~kg}\right.$ de termofosfato $\left./ \mathrm{m}^{3}\right)$ & $15,65 \mathrm{AB}$ & $143,40 \mathrm{~A}$ & 9,2 \\
\hline $\mathrm{F}$ & $4,04^{*}$ & $3,35^{*}$ & \\
\hline $\mathrm{CV}(\%)$ & 10,4 & 9,7 & \\
\hline \multicolumn{4}{|c|}{ Época de avaliação 6 (maio/2009) } \\
\hline 1 (Testemunha, sem fósforo) & $14,45 \mathrm{~B}$ & $133,27 \mathrm{~B}$ & 9,2 \\
\hline $2\left(2,5 \mathrm{~kg}\right.$ superfosfato simples $+186 \mathrm{~g}$ óxido $\left./ \mathrm{m}^{3}\right)$ & $16,60 \mathrm{AB}$ & $156,32 \mathrm{~A}$ & 9,5 \\
\hline $3\left(5,0 \mathrm{~kg}\right.$ superfosfato simples $+372 \mathrm{~g}$ óxido $\left./ \mathrm{m}^{3}\right)$ & $16,75 \mathrm{AB}$ & $154,15 \mathrm{~A}$ & 9,2 \\
\hline $4\left(3,1 \mathrm{~kg}\right.$ de termofosfato/m $\left.\mathrm{m}^{3}\right)$ & $17,95 \mathrm{~A}$ & $164,85 \mathrm{~A}$ & 9,2 \\
\hline $5\left(6,2 \mathrm{~kg}\right.$ de termofosfato $\left./ \mathrm{m}^{3}\right)$ & $16,75 \mathrm{AB}$ & $161,25 \mathrm{~A}$ & 9,6 \\
\hline $\mathrm{F}$ & $5,35^{*}$ & $18,94^{* *}$ & \\
\hline $\mathrm{CV}(\%)$ & 6,6 & 3,7 & \\
\hline
\end{tabular}




\section{CONCLUSÕES}

- A aplicação do fósforo incrementou o crescimento das plantas durante todo o ciclo de crescimento das mudas de seringueira.

- Para produção de mudas de seringueira, indica-se aplicação do fósforo na forma de termofosfato magnesiano na dose de $3,1 \mathrm{~kg}$ por $\mathrm{m}^{3}$ de terra ou na forma do superfosfato simples na dose de $2,5 \mathrm{~kg}$ por $\mathrm{m}^{3}$ de terra.

\section{AGRADECIMENTOS}

A Fertilizantes Mitsui S.A., pelo auxílio financeiro concedido.

\section{REFERÊNCIAS}

ASAWATRERATANAKUL, K.; ZHANG Y-W.; WITITSUWANNAKUL, D.; WITITSUWANNAKUL, R.; TAKAHASHI, S.; RATTANAPITTAYAPORN, A.; KOYAMA, T. Molecular cloning, expression and characterization of cDNA encoding cis-prenyltransferases from Hevea brasiliensis. European Journal Biochemistry, Berlin, v. 270, p. 4671-4680, 2003.

BALDEÓN, J. R. M. Efeito da ação alcalinizante e do silício na eficiência do termofosfato magnesiano em solos ácidos. Piracicaba, 1995. 92 p. Tese (Doutorado em Solos e Nutrição de Plantas) Escola Superior de Agricultura "Luiz de Queiroz", Universidade de São Paulo, 1995.

BENESI, J. F. C. A cultura da seringueira para o Estado de São Paulo. Campinas: CATI, 1999. 90 p.

CARVALHO, A. C. A.; BATISTA, E. M. Efeito da aplicação do fósforo no desenvolvimento da seringueira (Hevea brasiliensis Muell. Arg.). Macapá: Embrapa Amapá, 2004. 25 p. (Embrapa Amapá. Boletim de Pesquisa e Desenvolvimento, 70).

FARIA, C. M. B. de; SILVA, D. J.; PINTO, J. M.; GOMES, T. C. A. Efeito de fosfatos naturais em plantas de melão cultivadas em vasos. Revista Brasileira de Ciência do Solo, Viçosa, v. 30, n. 6, p. 1083-1091, 2006.

GOEDERT, W. J.; LOBATO, E. Avaliação agronômica de fosfatos em solo de cerrado. Revista Brasileira de Ciência do Solo, Viçosa, v. 8, p. 97-102, 1984.

GONÇALVES, P. S.; CARDOSO, M.; ORTOLANI, A. A. Origem, variabilidade e domesticação da Hevea: uma revisão. Pesquisa Agropecuária Brasileira, Brasília, v. 25, n. 2, p. 135-156, fev. 1990.

GONZAGA, R. L.; MENDONÇA, V.; SMARSI, R. C.; TOSTA, M. S.; BISCARO, G. A.; TOSTA, P. A. F. Utilização de termofosfato magnesiano na produção de mudas porta-enxerto de nespereira. Pesquisa Agropecuária Tropical, Goiânia, v. 38, n. 3, p. 195-200, 2008.

LANA, R. M. Q.; ZANAO JÚNIOR, L. A.; LUZ, J. M. Q.; SILVA, J. C. da. Produção da alface em função do uso de diferentes fontes de fósforo em solo de Cerrado. Horticultura Brasileira, Campinas, v. 22, n. 3, p. 525-528, 2004.

MELO, B.; MARCUZZO, K. V.; TEODORO, R. E. F.; CARVALHO, H. P. Fontes e doses de fósforo no desenvolvimento e produção do cafeeiro, em um solo originalmente sob vegetação de cerrado de Patrocínio-MG. Ciência e Agrotecnologia, Lavras, v. 29, n. 2, p. 315-321, 2005.

MORELLI, J. L.; NELLI, E. J.; BAPTISTELLA, J. R.; DEMATTÊ, J. L. I. Termofosfato na produtividade da cana-de-açúcar e nas propriedades químicas de um solo arenoso de baixa fertilidade. Revista Brasileira de Ciência do Solo, Campinas, v. 15, p. 57-61, 1991.

OLIVEIRA, E. L. de; MUZILLI, O.; IGUE, K.; TORNERO, M. T. T. Avaliação da eficiência agronômica de fosfatos naturais. Revista Brasileira de Ciência do Solo, Campinas, v. 8, p. 63-67, 1984.

PRADO, R. M. Nutrição de plantas. São Paulo: Editora UNESP, 2008. 407 p.

RAIJ, B. V. Fertilidade do solo e adubação. Piracicaba: Agronômica Ceres, 1991. 
SHORROCKS, V. M. Mineral deficiences in Hevea and associated cover plants. Rubber Res. Inst. of Malaya, 1964. $76 \mathrm{p}$.

YASUDA, M. Comportamento de fosfatos silicatados em solo de cerrado. Piracicaba, 1989. 62 p. Dissertação (Mestrado em Solos e Nutrição de Plantas) - Escola Superior de Agricultura "Luiz de Queiroz", Universidade de São Paulo, 1989. 